\title{
GRUPO ESCOLAR PROFESSSOR TIBÚRCIO DE FREITAS: ENTRE VESTÍGIOS E MEMÓRIAS- URUSSANGA (1928 - 1941)
}

\section{EACHING GROUP PROFESSOR TIBÚRCIO DE FREITAS: BETWEEN TRADES AND MEMORIES - URUSSANGA (1928 to 1941)}

\section{Shirlei Serafim de Oliveira ${ }^{1}$}

Giani Rabelo

\begin{abstract}
RESUMO: De acordo com o histórico da Escola de Educação Básica Barão do Rio Branco este estabelecimento dá início as suas atividades com a denominação de Grupo Escolar Tibúrcio de Freitas, no ano de 1928. No ano de 1941 a escola é transferida para um prédio próprio e sua denominação muda para Grupo Escolar Barão do Rio Branco. No trabalho de levantamento de documentos para a organização do Arquivo Histórico da EEB Barão do Rio Branco, foram encontrados alguns documentos do antigo Grupo Escolar Professor Tibúrcio de Freitas. Em contato com estes registros houve a necessidade de investigar sobre a trajetória de mais de uma década do Grupo Escolar Professor Tibúrcio de Freitas, na perspectiva de seus ex-alunos/as. Diante desta problemática foram traçados os seguintes objetivos específicos: reconstruir a história do Grupo Escolar Professor Tibúrcio de Freitas, no contexto da criação dos Grupos Escolares em Santa Catarina durante os anos de 1930; perceber o momento de emergência do Grupo Escolar Professor Tibúrcio de Freitas no cenário da cidade de Urussanga (SC); buscar pistas nos documentos do Grupo Escolar Tibúrcio de Freitas sobre o funcionamento e o público atendido pela escola. A metodologia utilizada para o desenvolvimento da pesquisa foi de abordagem qualitativa. Além da análise dos documentos do Grupo Escolar Tibúrcio de Freitas, foram realizadas entrevistas semiestruturadas, a fim de coletar depoimento de dois ex-alunos e uma ex-aluna que estudaram na instituição, entre os anos de 1928 a 1941. A partir dos documentos analisados e depoimentos obtidos é possível afirmar que a a escola tradicional subsistiu, mesmo no contexto de inovação educacional demarcado pela introdução do Grupo Escolar. Há indícios, a partir destas lembranças que o castigo e a memorização foram bastante utilizados enquanto recursos pedagógicos. $\mathrm{O}$ processo de passagem de uma pedagogia tradicional para uma pedagogia moderna, parece não se tratar de um processo linear, há avanços e retrocessos, permanências e descontinuidades.
\end{abstract}

PALAVRAS CHAVE: História das Instituições Educativas. Arquivo Escolar. Memória. Grupo Escolar Professor Tibúrcio de Freitas. .

\footnotetext{
${ }^{1}$ Graduada em Pedagogia da UNESC - tenente.shirlei@ gmail.com

${ }^{2}$ Professora do Curso de Pedagogia e do Programa de Pós-graduação em Educação da UNESC - gra@ unesc.net. Saberes Pedagógicos, Criciúma, v. 4, nº1, janeiro/abril 2020.-Curso de Pedagogia- UNESC
} 
KEYWORDS: According to the history of the School of Basic Education Barão do Rio Branco this establishment began its activities with the denomination of Grupo Escolar Tibúrcio de Freitas, in the year of 1928. In the year of 1941 the school is transferred to a proper building and its denomination changes to Grupo Escolar Barão do Rio Branco. In the work of collecting documents for the organization of the Historical Archive of BSE Barão do Rio Branco, some documents of the former School Group Professor Tibúrcio de Freitas were found. In contact with these records there was a need to investigate the trajectory of more than a decade of Professor Tiburcio de Freitas School Group, from the perspective of his former students. In view of this problem, the following specific objectives were set out: to reconstruct the history of the Professor Tibúrcio de Freitas School Group, in the context of the creation of the School Groups in Santa Catarina during the 1930s; to perceive the moment of emergency of the School Group Professor Tibúrcio de Freitas in the scenario of the city of Urussanga (SC); look for clues in the documents of the Tibúrcio de Freitas School Group about the operation and the public attended by the school. The methodology used for the development of the research was qualitative approach. In addition to the analysis of the documents of the Tibúrcio de Freitas School Group, semi-structured interviews were conducted in order to collect testimony from two former students and a former student who studied at the institution between the years of 1928 and 1941. From the documents analyzed and testimonies obtained it is possible to affirm that the traditional school survived, even in the context of educational innovation marked by the introduction of the School Group. There are indications, from these memories, that punishment and memorization were widely used as pedagogical resources. The process of moving from a traditional pedagogy to a modern pedagogy does not seem to be a linear process, there are advances and setbacks, permanences and discontinuities.

KEYWORDS: History of Educational Institutions. School Archive. Memory. School Group Teacher Tibúrcio de Freitas.

\section{INTRODUÇÃO}

Durante minha trajetória acadêmica como aluna do Curso de Pedagogia da Universidade do Extremo Sul Catarinense- UNESC, fui contemplada com duas bolsas de pesquisa no Programa Institucional de Bolsas de Iniciação Científica (PIBIC). Entre o segundo semestre do ano de 2016 e o primeiro semestre de 2017, participei da execução do Plano de Trabalho intitulado "A situação do acervo documental das escolas que compõem o Centro de Memória da Educação do Sul de Santa Catarina (virtual) - CEMESC: diagnóstico e orientações para a conservação e preservação (segunda etapa) ". No segundo semestre de 2017 até o primeiro semestre de 2018 participei de outro projeto denominado: “Conservação e preservação do patrimônio educativo da EEB Barão do Rio Branco (Urussanga): o arquivo histórico como lugar de memória", que ainda está em andamento. Tanto no primeiro projeto

Saberes Pedagógicos, Criciúma, v. 4, nº1, janeiro/abril 2020.- Curso de Pedagogia- UNESC 
quanto no segundo atuei junto aos membros do Grupo de Pesquisa História e Memória da Educação - GRUPEHME e do Centro de Memória e Documentação da UNESC- CEDOC.

No primeiro plano privilegiaram-se as atividades voltadas as escolas que compõem o acervo do Centro de Memória da Educação do Sul de Santa Catarina CEMESSC (virtual) ${ }^{3}$, a fim de fazer a devolutiva do referido centro e sensibilizar a comunidade escolar sobre a importância da preservação do patrimônio histórico escolar. Já no segundo, as atividades concentraram-se em torno da EEB Barão do Rio Branco, localizada no município de Urussanga (SC), uma das escolas que fazem parte do CEMESSC. Nesta, o trabalho foi voltado para a organização do arquivo histórico e a criação de um centro de memória físico.

Durante os trabalhos de devolutiva do CEMESSC junto às escolas envolvidas ${ }^{4}$ diagnosticamos várias necessidades no domínio da conservação e preservação do patrimônio histórico escolar, principalmente no que diz respeito às práticas de conservação, higienização e cuidados com o arquivo documental permanente, temporário e corrente. A partir das reuniões realizadas, no primeiro projeto, tendo como público alvo professores/as e equipes diretivas, muitos/as relataram que não havia um responsável pela organização e preservação dos arquivos históricos (permanente) e em muitos casos estes ficavam expostos às pragas e às más condições de conservação.

No segundo projeto, após o processo de levantamento de dados e de pesquisa na EEB Barão do Rio Branco, tive acesso a grande parte do acervo documental mais antigo que ainda foi preservado e pude perceber a importância de conservá-los com intuito de fortalecer a identidade da instituição e de toda comunidade escolar. Pude perceber também que muitos sujeitos fizeram parte de sua história na condição de alunos/as, professores/as e funcionários/as e que colaboraram para que este estabelecimento fosse reconhecido na cidade e região. De acordo com o histórico da EEB Barão do Rio Branco (2018) este estabelecimento inicia suas atividades com a denominação de Grupo Escolar Professor Tibúrcio de Freitas, no ano de 1928. No ano de 1941, o grupo escolar é transferido para outro prédio e sua

\footnotetext{
${ }^{3}$ Artigo sobre o cemessc

${ }^{4}$ Escolas envolvidas trabalho apresentado semana c e $\mathrm{t}$
}

Saberes Pedagógicos, Criciúma, v. 4, nº1, janeiro/abril 2020.- Curso de Pedagogia- UNESC 


\section{SABERES PEDAGÓGICOS}

Revista do Curso de Graduaçāo de Pedagogia - Unesc

ISSN 2526-4559

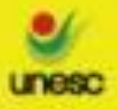

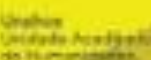

denominação muda para Grupo Escolar Barão do Rio Branco, atual EEB Barão do Rio Branco.

De acordo com Vendramini (2003), “o nome dado inicialmente ao grupo é uma homenagem ao professor Tibúrcio de Freitas, que nasce no Ceará em 1870. Mais tarde vem para Santa Catarina e se estabelece na cidade de Itajaí, onde se dedica ao magistério e ao jornalismo. Falece em 1915, na cidade do Rio de Janeiro”.

No levantamento de documentos para a organização do arquivo histórico deste educandário foram encontrados os seguintes documentos do antigo Grupo Escolar Professor Tibúrcio de Freitas: 1- Livro de Matrícula das alunas (23 de fevereiro de 1928 a 2 de março de 1928); 2- Livro de Matrícula de Alunos ( 23 de fevereiro de 1928 a 2 de março de 1928); 3- Livro Ponto dos Funcionários (15 de fevereiro de 1939 a 7 de junho de 1940); 4- Livro Ata de exames Finais (novembro de 1939 a novembro de 1940); 5- Livro Termo de Compromisso dos Funcionários ( 15 de fevereiro de 1928 a 27 de março de 1941); 6- Livro de Lançamento de Notas de Honra (23 de fevereiro de 1928 a 28 de março de 1941); 7- Certidão de Nascimento de Alicio Anselmo (20 de fevereiro de 1953); 8- Programa Festa Enceramento (12 de novembro de 1935); 9- Livro de Atas de Programação de Exames de Alunos da Escola Complementar de Urussanga (15 de fevereiro de 1934 a 27 março de 1941); 10- Livro Registro de Notas Sabatinas dos Alunos da Escola Complementar de Urussanga (15 de fevereiro de 1934 a 24 de julho de 1941).

Em contato com estes registros me senti muito instigada a investigar sobre a trajetória de mais de uma década do Grupo Escolar Professor Tibúrcio de Freitas, na perspectiva de seus ex-alunos/as. Diante disso, elaborei a seguinte questão de pesquisa: Que lembranças os alunos e alunas do Grupo Escolar Professor Tibúrcio de Freitas guardam sobre suas experiências escolares? A partir desta questão, como objeito geral, busquei compreender as experiências escolares que mais significaram para os estudantes do Grupo Escolar Professor Tibúrcio de Freitas, a partir de suas lembranças. Diante desta problemática foram traçados os seguintes objetivos específicos: reconstruir a história do Grupo Escolar Professor Tibúrcio de Freitas, no contexto da criação dos Grupos Escolares em Santa Catarina durante os anos de 1930; perceber o momento de emergência do Grupo Escolar Professor Tibúrcio de 
Freitas no cenário da cidade de Urussanga (SC); buscar pistas nos documentos do Grupo Escolar Professor Tibúrcio de Freitas sobre o funcionamento e o público atendido pela escola.

A metodologia utilizada para o desenvolvimento da pesquisa foi de abordagem qualitativa. Além da análise dos documentos do Grupo Escolar Professor Tibúrcio de Freitas, citados anteriormene, realizei uma pesquisa de campo com a utilização de entrevistas semiestruturadas, a fim de coletar depoimento de dois ex-alunos e uma ex-aluna que estudaram na instituição, entre os anos de 1928 a 1941.

\begin{abstract}
São cinco as características básicas da pesquisa qualitativa, chamada, as vezes, também de naturalística: a) A pesquisa qualitativa tem o ambiente natural como fonte direta de dados e o pesquisador como principal instrumento; b) os dados coletados são predominantemente descritos; c) a preocupação com o processo é muito maior do que com o produto; d) o significado que as pessoas dão às coisas e à sua vida são focos de atenção especial pelo pesquisador; e) a análise dos dados tende a seguir um processo indutivo (LUDKE, 1986, p. 44).
\end{abstract}

As três entrevistas foram gravadas e, posteriormente, transcritas. Após a transcrição, a entrevistas foram devolvidas aos sujeitos da pesquisa e os mesmos autorizaram o uso das informações por meio do Termo de Consentimento (Anexo B).

Este estudo ocorreu no campo da história da educação, mais precisamente no âmbito da história das instituições educativas. Partiu-se do entendimento que:

\begin{abstract}
As instituições educativas são organismos vivos, cuja integração numa política normativa e numa estrutura educativa de dimensão nacional e internacional é fator de conflito entre os campos da liberdade, criatividade, sentido crítico e autonomização dos atores e o normativismo burocrático e político-ideológico estruturante (MAGALHAES, 1998, p. 124).
\end{abstract}

Neste viés, as instituições educativas são complexas e atravessadas por diferentes interesses. Nela encontramos diferentes concepções e práticas educacionais que nem sempre acompanham o que prescreve as políticas educacionais vigentes em cada época.

É preciso frisar que o Grupo Escolar Professor Tibúrcio de Freitas é um lugar de memória, por isso a importância de preservar seus registros e as lembranças daqueles e daquelas que fizeram parte de sua trajetória. Neste sentido, compreendo que:

Saberes Pedagógicos, Criciúma, v. 4, nº 1, janeiro/abril 2020.- Curso de Pedagogia- UNESC 


\section{SABERES PEDAGÓGICOS}

Revista do Curso de Graduaçāo de Pedagogia - Unesc

ISSN $2526-4559$
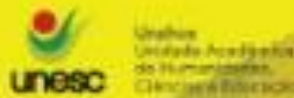

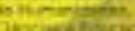

Os lugares de memória nascem e vivem do sentimento de que não há memória espontânea, que é preciso criar arquivos, que é preciso manter aniversários, organizar celebrações, pronunciar elogios fúnebres, notariar atas, porque essas operações não são naturais (NORA, 1993, p. 13).

O artigo está organizado em três momentos. Num primeiro momento contextualizo a criação do Grupo Escolar Professor Tibúrcio de Freitas no cenário demarcado pela criação dos grupos escolares em Santa Catarina, nos anos de 1930; em seguida, busco perceber o momento de emergência do Grupo Escolar Professor Tibúrcio de Freitas no cenário da cidade de Urussanga (SC): na sequência procuro conhecer a comunidade escolar e as práticas docentes a partir dos registros escolares e, por último, problematizo algumas lembranças sobre as experiências escolares de alunos e alunas do Grupo Escolar Professor Tibúrcio de Freitas.

\section{A CRIAÇÃO DO GRUPO ESCOLAR PROFESSOR TIBÚRCIO DE FREITAS NOS ANOS DE 1930 EM SANTA CATARINA}

Parte compreendermos melhor a transformação educacional brasileira ocorrida no início do século XX, precisamos entender a emergência dos Grupos Escolares, instituição educativa que deu início ao emprego de novas metodologias de ensino, denominada pedagogia moderna. Os primeiros grupos escolares foram criados em São Paulo. A presença de um Grupo Escolar em qualquer cidade era tida como referencial de modernidade social, cultural e política, ou seja, estes passam a ser a grande referência no campo educacional. Tanto que a construção dos Grupos Escolares, quando ocorriam, toda a manobra política da época se fazia presente durante sua inauguração, muitos destes grupos levavam em seus nomes, nomes de personalidades políticas que estavam em destaque na época, como se fossem homenagens a tal político. A fim de colocar na esteira da modernidade, tinha como objetivo unificar as escolas isoladas em um único local (prédios projetados para serem escolas), reduzindo assim custos financeiros, mas também o aprimoramento da metodologia de ensino. Como destaca Rossi:

Saberes Pedagógicos, Criciúma, v. 4, nº 1, janeiro/abril 2020.- Curso de Pedagogia- UNESC 


\title{
SABERES PEDAGÓGICOS
}

Revista do Curso de Graduaçāo de Pedagogia - Unesc

ISSN 2526-4559

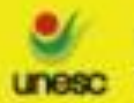

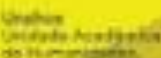

ine intision:

\begin{abstract}
A modernização técnica-cientifica aplicada a organização do espaço e dos saberes escolares ecoa em muitas direções. Elas podem ser percebidas na criação dos grupos escolares e na remodelação das escolas reunidas, revelando os sentidos empregados na nacionalização da vida social. Essa racionalização construiu, ao longo do processo, o modelo graduado de ensino que s expandiu, nas primeiras décadas republicanas, como uma instituição educacional almejada não apenas por governantes, mas também por outros sujeitos, como diretores de ensino e professores (ROSSI, 2017, p. 318).
\end{abstract}

Em Santa Catarina, o Grupo Escolar chega primeiramente na cidade de Joinville, através do então Governador Vidal Ramos, do Partido Republicano Catarinense (1910 1914), sendo assim, o "Collégio Municipal de Joinville", tornou-se o primeiro Grupo Escolar do Estado de Santa Catarina, cuja denominação foi Grupo Escolar Conselheiro Mafra, inaugurado em 15 de novembro de 1911. Após este evento, no Estado de Santa Catarina acontece a inauguração de mais oito Grupos Escolares: Grupo Escolar Jerônimo Coelho (Laguna), Grupo Escolar Lauro Muller (Florianópolis), Grupo Escolar Victor Meirelles (Itajaí), Grupo Escolar Vidal Ramos (Lages), Grupo Escolar Silveira de Souza (Florianópolis), Grupo Escolar Hercílio Luz (Tubarão), datados de novembro de 1911 a 1920 (SILVA, 2006).

Figura 1: Segundo Grupo Escolar de Santa Catarina - Grupo Escolar Jerônimo Coelho, inaugurado em 12 de dezembro de 1912

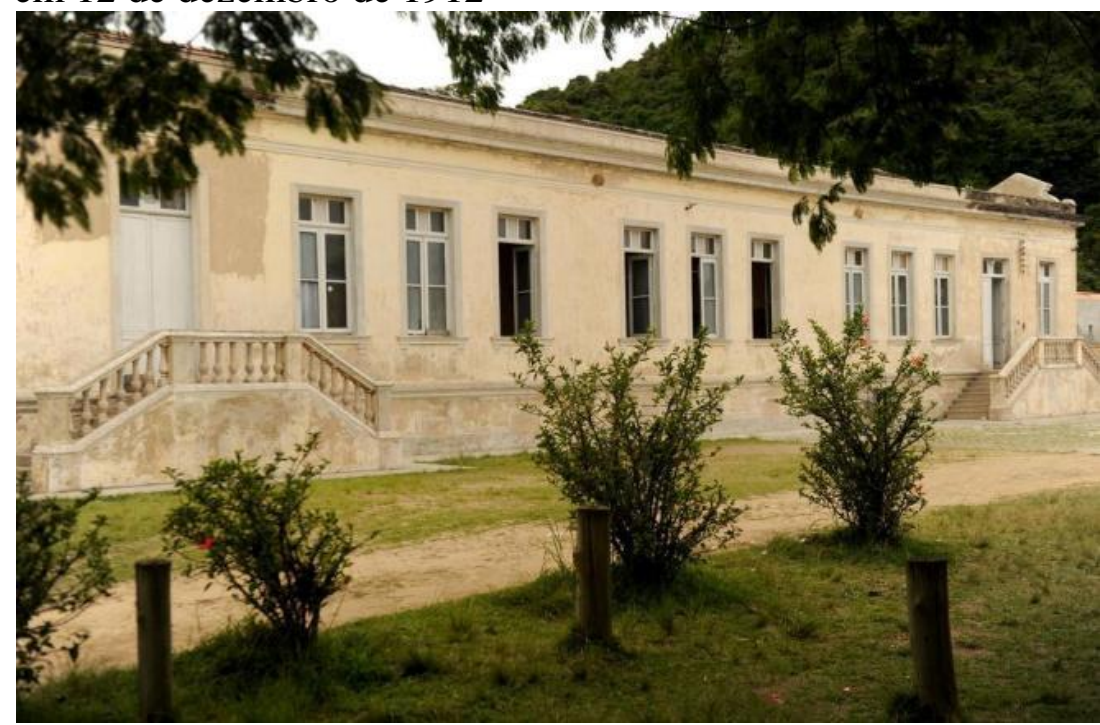

Fonte: Diário Catarinense (2018, p.1)

Saberes Pedagógicos, Criciúma, v. 4, nº 1, janeiro/abril 2020.- Curso de Pedagogia- UNESC 
É importante enfatizar que existiam alguns aspectos em comum nos diferentes projetos que atendiam uma exigência da época: a separação das alas femininas e masculinas, que nos edifícios de dois pavimentos cada pavimento era destinado para um sexo. Já nos edifícios térreos, as alas eram opostas, inclusive com relação ao recreio. Nota-se que as construções, apesar de existir o pátio central, o mesmo não era utilizado pelos alunos (SANTOS, 2008, p.10).

Em nível estadual, acompanhando o movimento de renovação educacional do país, Santa Catarina no início do século XX começa a reforma da instrução pública e neste processo a Pedagogia Moderna e a Escola Nova são dois modelos pedagógicos presentes nos discursos dos intelectuais da educação. Pedagogia Moderna tem seu foco na desnaturalização da educação tradicional, que tinha como eixo central a memorização por parte dos estudantes no processo ensino aprendizagem. Já a Escola Nova traz consigo o estudante como centro, onde o interesse dele é relacionado às atividades propostas. Esta vertente pedagógica foi introduzida por meio da Lei 846/1910 que passa a vigorar a partir de 1911 (Reforma da Instrução Pública), ocorrida no governo de Vidal Ramos, sob a supervisão de Orestes Guimarães. Este, por sua vez, teve papel fundamental na implantação deste novo modelo educacional, no que se refere à reorganização do ensino, adequando-o às necessidades da época. Com um currículo de experiência no Estado de São Paulo ele é nomeado Inspetor Geral da Instrução Pública no ano anterior, em 1910 (COSTA, 2016).

Com o passar dos anos, novas reformas foram necessárias no âmbito educacional, e em 1935 a Reforma da Trindade toma dimensão muito maior, baseada no VI Congresso de Educação, metodologia do ensino do Distrito Federal coordenado, em 1928, por Fernando Azevedo. O professor Luiz Sanches Bezerra da Trindade é o responsável por reorganizar o ensino catarinense. Tornou as Escolas Normais em Instituições Escolares, abrangendo Jardim da Infância, Grupo Escolar, Escola Isolada (tipo rural), Escola Normal Primária, Escola Normal Secundária e Escola Normal Superior Vocacional (COSTA, 2016).

A Reforma Elpidio Barbosa ocorre em 1946, sendo assim a última reforma para os grupos escolares, trazendo consigo uma nova visão para modificações vindas através da Lei Orgânica Federal do Ensino Primário, A Lei № 8.529 de 02 de janeiro de 1946, pretendia inserir ao cotidiano escolar a cultura social e o conhecimento sobre o país, a fim de fortalecer o comprometimento com a vida social e nacional por parte dos estudantes. A referida lei promoveu o acesso escolar dos alunos, dos sete aos doze anos de idade, além disso, buscou

Saberes Pedagógicos, Criciúma, v. 4, nº1, janeiro/abril 2020.- Curso de Pedagogia- UNESC 
estabelecer condições adequadas para o desenvolvimento da personalidade dos estudantes e aprimorar os conhecimentos relacionados a família, saúde e a inicialização ao trabalho profissional (SOUZA, 2016).

Vale ressaltar que os belos prédios arquitetados na primeira leva dos grupos escolares em Santa Catarina, não era a realidade da segunda leva de construções, que ocorre entre os anos de 1920 a 1940. Tal realidade pode ser observada por meio dos históricos das escolas mais antigas, conforme consta no acervo virtual do CEMESSC. São escolas que foram construídas, em geral, com recursos da comunidade local e, posteriormente, são transformadas em Grupos Escolares.

De acordo com as informações coletadas no banco de dados do CEMESSC, é possível trazer alguns exemplos: o Grupo Escola Costa Carneiro (1935) Orleans, contou com o apoio financeiro do Sr. Luiz Verani Cascaes, o Grupo Escolar José do Patrocínio (1955) de Treviso contou com a doação de terreno do Sr. José Feltrin e Sra. Maria Gamba Feltrin (CEMESSC, 2018). Diante desses exemplos, poderíamos observar que a segunda leva dos grupos escolares já não era mais o centro da prioridade orçamentária e política dos governantes subsequentes. No excerto abaixo, isso fica evidente:

\footnotetext{
A partir de 1915, foi criado um tipo de escola intermediária entre as escolas isoladas e os grupos escolares, denominadas escolas reunidas. As escolas isoladas de primeiras letras e as escolas reunidas continuavam em funcionamento no estado ao lado dos grupos escolares. Em 1930, fora de nosso período de estudo, apareceram os primeiros grupos escolares para a periferia, mediante poucos recursos e em prédios mais simples; as escolas reunidas transformaram-se em grupos escolares de pequeno porte (CARDOSO, HOFF, MAFRA, 2007, p. 16)
}

No Sul de Santa Catarina, mais precisamente na cidade de Urussanga, o Grupo Escolar Professor Tibúrcio de Freitas foi o pioneiro na região. Ele emergiu da antiga escola idealizada pelo padre Luigi Marzano que foi projetada por um amigo engenheiro e construída com a utilização de recursos financeiros oriundos do governo italiano. No início, esta escola era administrada por religiosas, como uma espécie de internato. No próximo item será tratado sobre os antecedentes do Grupo Escolar Professor Tibúrcio de Freitas e sua emergência na cidade de Urussanga (SC).

Saberes Pedagógicos, Criciúma, v. 4, nº 1, janeiro/abril 2020.- Curso de Pedagogia- UNESC 


\section{EMERGÊNCIA DO GRUPO ESCOLAR PROFESSOR TIBÚRCIO DE FREITAS NO CENÁRIO DA CIDADE DE URUSSANGA (SC)}

O Grupo Escolar Professor Tibúrcio de Freitas tem início na antiga escola criada pelo Pe. Luigi Marzano na cidade de Urussanga (SC). Natural de Piemonte, localizada ao norte da Itália, ao chegar em Urussanga, no ano de 1899, o Pe. Luigi Marzano deparou-se com a cidade em condições muito precárias, desde a falta de assistência médica, até a falta de instrução escolar. Através de recursos vindos do governo italiano o referido padre dá início ao projeto de construção da primeira escola, com o objetivo de atender filhos e filhas de imigrantes italianos (COSTA, 2011).

Sem recursos ele busca ajuda de um amigo engenheiro, que faz a planta do prédio. Posteriormente é apresentada ao governo italiano e na sequência dá início a obra. No entanto, o padre não consegue presenciar a mesma finalizada, pois é convocado a retornar para sua cidade natal na Itália. As aulas, inicialmente são ministradas por freiras vindas Itália (COSTA, 2011).

O Pe. Marzano deixa registrado a chegada, as lutas e as conquistas dos imigrantes italianos em sua obra intitulada "Colonos e Missionários Italianos: nas Florestas do Brasil" datada de 1985. Esta obra retrata os acontecimentos da época, na visão do padre, e procura traduzir o sentimento do povo italiano ao chegar no Brasil, em busca de uma nova vida e novas oportunidades na região sul do país.

Estes imigrantes chegam do norte da Itália, principalmente da região de Veneto e Lombardia, povoando as colônias de Azambuja, Urussanga e Tubarão. Entre essas a mais importante foi seguramente, Urussanga, que fundada em 1878, chegou a ter 17 núcleos coloniais e constituiu o único município italiano de Santa Catarina, contando, no início do século XX, com 7.000 habitantes, quase todos do norte da Itália (TRENTO, 1898, p. 86).

Os imigrantes italianos vêm com a promessa de melhoria de vida, na esperança de encontrar no Brasil novas oportunidades, pois em seu país de origem isso não era possível devido a unificação política existente na Itália entre 1876 e 1878. Ao chegarem no Brasil, os imigrantes italianos eram recepcionados pelo diretor da colônia, no caso de Urussanga o

Saberes Pedagógicos, Criciúma, v. 4, nº1, janeiro/abril 2020.- Curso de Pedagogia- UNESC 


\title{
SABERES PEDAGÓGICOS
}

Revista do Curso de Graduaçāo de Pedagogia - Unesc

ISSN 2526-4559

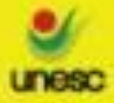

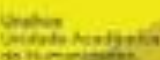

responsável era o $\mathrm{Sr}^{\mathbf{0}}$ Joaquim Vieira Ferreira (MARZANO, 1985). Sobre esse processo, Selau (2006, p. 116) comenta:

\begin{abstract}
Entretanto, a resistência dos Xoklengs ao convívio com a civilização é um exemplo de resistência de muitos povos em não acreditar pura e simplesmente esta dominação. Dentro deste quadro, o território ocupado pelos Xoklengs passou a ser ocupado por colônias formadas pelo governo e habitadas, no sul catarinense, majoritariamente por imigrantes europeus.
\end{abstract}

De acordo com Costa (2011), o Pe. Marzano era muito respeitado entre os moradores locais. No campo político, teve grande influência no processo de municipalização da cidade de Urussanga, quando foi negada sua emancipação pelos políticos da época.

Urussanga torna-se município no dia 22 de janeiro de 1901 e tem como primeiro prefeito o senhor Jacinto Brida. Após este marco para a cidade, muitas mudanças foram acontecendo para o desenvolvimento local. Situada ao Sul do Estado de Santa Catarina, a cidade de Urussanga fica há 190 quilômetros da Capital Florianópolis/SC. Segundo dados de pesquisa do IBGE de 2010, a cidade conta com aproximadamente 21.177 habitantes.

Quanto a educação de seus filhos e filhas, os imigrantes, a exemplo de outros grupos de outras nacionalidades que chegaram durante o século XIX ao Brasil, criaram as “escolas étnicas". Há indícios que a escola criada pelo Pe. Marzano, no início, quando as freiras italianas eram professoras, tenha se configurado como uma escola étnica italiana.

De acordo com Fiori (1991), os estabelecimentos públicos de ensino das zonas coloniais, eram insuficientes para toda a população escolar. Além disso, os imigrantes não apreciavam matricular seus filhos nessas escolas, seja por preferirem que suas crianças fossem escolarizadas no idioma dos antepassados, seja por terem - os imigrantes e os alunosdificuldades de comunicação verbal com os mestres de escolas públicas, que falavam apenas o português.

No entanto, estas escolas irão sofrer interdições com o Estado Novo (1937-19450) com o processo de nacionalização do ensino. Para Baldin (1999 apud Vendramini, 2003, p. 32-33):

Figura 2: Prédio onde funcionou o antigo Grupo Escolar Professor Tibúrcio de Freitas (16 de outubro de 2018)

Saberes Pedagógicos, Criciúma, v. 4, n¹, janeiro/abril 2020.- Curso de Pedagogia- UNESC 


\section{SABERES PEDAGÓGICOS}

Revista do Curso de Graduaçāo de Pedagogia - Unesc

ISSN 2526-4559

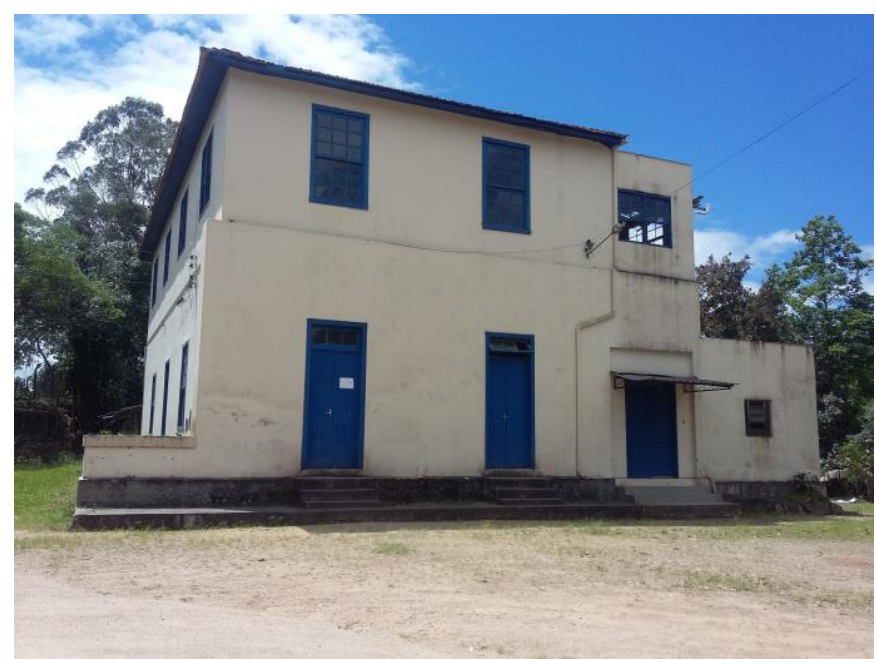

Fonte Acervo particular da pesquisadora.

As escolas coordenadas por padres ou freiras italianas sofrem perseguições por serem consideradas focos de resistência ao nacionalismo. Por questões políticas, o padre Marzano parte em 1908, e as freiras, em 1923. Outras freiras desta mesma congregação voltam a Urussanga em 199833 para administrar o hospital. O Inspetor Escolar para as escolas italianas, Luigi Peroni, também encontra dificuldades para permanecer em Urussanga, por ser um nacionalista italiano, retornando à Itália.

A criação do Grupo Escolar Professor Tibúrcio de Freitas e as tentativas anteriores em atender a demanda educacional atravessou este contexto demarcado pelo processo de criação de escolas étnicas, o processo de nacionalização e modernização educacional, em detrimento de uma escola elitista e tradicional existente e mantida, principalmente, pela igreja católica. No campo educacional, o Grupo Escolar representará a tentativa de materializar uma escola moderna, como já foi mencionado.

Sobre a escola das religiosas que funcionou no mesmo prédio construído pelo Pe. Marzano, atual Paraiso da Criança, não se tem informações, o que demandaria um estudo mais aprofundado a este respeito.

Os documentos encontrados no acervo da EEB.Barão do Rio Branco que pertenciam ao Grupo Escolar Professor Tibúrcio de Freitas nos dão algumas pistas sobre a criação e funcionamento da escola, além do seu corpo docente e estudantil e as formas de avaliação da aprendizagem, entre 1928 a 1941.

Saberes Pedagógicos, Criciúma, v. 4, nº 1, janeiro/abril 2020.- Curso de Pedagogia- UNESC 


\section{OS DOCUMENTOS DO GRUPO ESCOLAR PROFESSOR TIBURCIO DE}

\section{FREITAS: algumas pistas sobre a comunidade escolar e as práticas docentes.}

O acervo documental de uma instituição escolar pode revelar questões importantes para nós educadores, principalmente no que diz respeito a forma de como nossa prática docente está sendo trabalhada. Nossas práticas foram e são construídas historicamente. Os documentos escolares também nos ajudam a entender os valores e princípios morais e éticos de cada sociedade, pois estes se materializam no cotidiano escolar. Portanto, os documentos podem ser analisados como testemunhos, que podem ser interpretados de diferentes perspectivas e olhares. No acervo do Grupo Escolar Professor Tibúrcio de Freitas encontramos alguns registros de ordem administrativa. Neste trabalho, parte-se do princípio que:

\footnotetext{
Os arquivos e os seus documentos têm adquirido uma importância crescente no campo da história da educação. Eles possuem informações que per- mitem introduzir a uniformidade na análise reali- zada sobre os vários discursos que são produzidos pelos actores educativos — professores, alunos, funcionários, autoridades locais e nacionais têm representações diversas relativamente à escola e expressam-nas de formas diversificadas. $\mathrm{O}$ arquivo, constituindo o núcleo duro da informação sobre a escola, corresponde a um conjunto homogéneo e ocupa um lugar central e de referência no universo das fontes de informação que podem ser utilizadas para reconstruir o itinerário da instituição escolar. (MOGARRO, 2005, p. 72)
}

Nos dois livros de matrícula, um com a relação dos nomes de alunos e outro com a relação de nome de alunas, datados de 23 de fevereiro de 1928, a ordem das informações é a seguinte: número de matrícula, número de ordem, nomes por ordem alfabética, dia, mês e ano de seus nascimentos, filiação, local de origem, profissão do pai, cidade de residência, além de espaço reservado para observações.

No livro de matricula dos alunos o primeiro nome que aparece na lista dos matriculados, no $1^{\circ}$ ano, é de Aldo Bresciani, nascido em 25 de abril de 1919. Ele é natural de Urussanga, filho do senhor João Bresciani que à época exercia a profissão de Padeiro. Este mesmo livro contém 50 páginas e traz consigo as profissões, em geral, exercidas pelo pai do aluno, tais como: Artista, Açougueiro, Comerciante, Carpinteiro, Dentista, Doméstica, Empregado Público, Empregado Federal, Ferreiro, Fabricante, Funileiro, Fazendeiro,

Saberes Pedagógicos, Criciúma, v. 4, nº1, janeiro/abril 2020.- Curso de Pedagogia- UNESC 


\section{SABERES PEDAGÓGICOS}

Revista do Curso de Graduaçāo de Pedagogia - Unesc

ISSN 2526-4559

Funcionário Público, Farmacêutico, Hoteleiro, Industrial, Jornaleiro, Latoeiro, Lavrador, Maquinista, Negociante, Operário, Ourives, Oficial do Exército, Promotor, Sapateiro, Sodado, Seleiro, Serrador e Telegrafista. Chama a atenção que uma única profissão se refere à exercida por uma mãe de aluno, ou seja, Doméstica.

As cidades e localidades de origem dos estudantes eram: Urussanga, Morro da Fumaça, Treviso, Tubarão (Azambuja), Belvedere, Palhoça, Jaguaruna, Caeté, Araranguá, Rio Maior, Içara, Rio Alto, Esplanada, Curitiba, Tubarão, Rio Américo, Tubarão (Palmeiras), Orleans, São Paulo, Pedras Grandes, Nova Veneza, Rio Carvão, Novo Horizonte, Porto Bello, Cocal, Tijucas, Camboriú, Lauro Muller, Blumenau, Meleiro, Rio Deserto, Linha Torres, Rio Hypolitho, Laguna, Linha Rio Caethé. Estas informações levam a supor que Urussanga recebe além dos imigrantes italianos e seus descendentes, os moradores de outras cidades, não só da região do extremo sul catarinense, mas também oriundos de outros estados, como Paraná e São Paulo.

Os sobrenomes, em grande medida, evidenciam a forte presença de descendentes italianos no Grupo Escolar Professor Tibúrcio de Freitas. Os sobrenomes identificados foram: Ávila, Anacleto, Abreu, Bacha, Brida, Bainha, Bettiol, Barros, Baldin, Bona, Burigo, Buogo, Bez Batti, Bresciani, Brolini, Bom, Campos, Crema, Calviso, Cruz, Cechinel, Concher, Cascaes, Cordella, Costa, Cadorin, Cataneo, Cassol, Duarte, De Piva, Damiani, Donadel, Doneda, Escaravaco, Flores, Faria, Furghesti, Freccia, Faveri, Fackini, Facin, Fontanella, Goulart, Hilbert, Inocêncio, Lavinia, Lima, Lavarizze, Lopes, Neves, Machado, Miotti, Mazzuco, Mac Donald, Mattos, Manarin, Moraes, Martinagno, Nardão, Oliveira, Pelegrin, Possamai, Pereira, Perraro, Pacheco, Pita, Piúco, Scarpa, Sartor, Salvador, Silva, Tonedo, Ticiani, Teixeira, Tasso, Teza, Trento, Virtuoso, Vaz, Virtuoso, Villa, Virgolino, Werpachowski, Zanini, Zanelato.

Amélio Zanelatto era um dos alunos mais velho entre os matriculados. Nascido no dia 9 de janeiro de 1914, estava com 14 anos na época e cursava o $4^{\circ}$ ano do Ensino Complementar (1928), seu pai o senhor Eugenio Zanelatto era Lavrador. O Grupo Escolar Professor Tibúrcio de Freitas oferecia os quatro anos primários, contava com aproximadamente 32 alunos/as matriculados/as no ano de 1928 e tinha como diretora e professora Eulina Marcelino.

Saberes Pedagógicos, Criciúma, v. 4, nº 1, janeiro/abril 2020.- Curso de Pedagogia- UNESC 


\section{SABERES PEDAGÓGICOS}

Revista do Curso de Graduaçāo de Pedagogia - Unesc

ISSN $2526-4559$

No Livro Termo de Compromisso dos Funcionários, datado de 15 de fevereiro de 1928 a 27 de março de 1941, constam os nomes dos/as seguintes professores/as: Djalma Bento (diretor), Outinha de Souza (servente), Odete Bilk (professora), Eugênio Marcheti (professor), Janice C. de Azevedo (adjunta), Hercílio De Faveri (professor), Orcy P. Silva (professora), Nelly de Carvalho (professora), Ruth Lebarbechon (professora), Maria do Carmo Ramos (professora), Omar Maciel Berendt (professor), Maria da Glória Matos (professora), Eulina Alves de Gouvêa Marcelino (professora), Emília Celestina Piazza (professora), Jacy Bainha (professora substituta).

No Livro Ponto de Compromisso dos Funcionários, datado de (15 de fevereiro de 1928 a 7 de junho de junho de 1940), constam as seguintes informações: data, nome, funcionários e designação de cargo ocupado, por fim, observações.

Sobre o desempenho escolar dos estudantes, no Livro Ata de Exames Finais (novembro de 1939 a novembro de 1940) constam informações importantes. Além dos itens de identificações dos alunos e alunas há o item classificação, que hierarquiza os estudantes em fracos, médios e fortes, bem como a data de eliminação (dia, mês), notas dos exames finais, as provas escritas (linguagem, aritmética, média, linguagem comentada) e a média de promoção, além de um espaço para as observações.

Um dos entrevistados para esta pesquisa, o senhor Armando Bettiol, hoje com 88 anos foi classificado como forte, aprovado com nota $100 \mathrm{em}$ todos os exames finais. Neste documento aparecem alguns nomes de professores/as: Odete Bilk, normalista, em exercício desde 1936. Eugenio Mascheti, normalista, em exercício no estabelecimento desde 1936, Hercílio de Faveri, normalista, em exercício desde 1939 e, por fim, a professora Emília Celestina Piazza (professora regente), vocacionista, em exercício desde 1939.

De acordo com a reportagem do Jornal Panorama, datado de 19 de agosto de 2011, o professor no Grupo Escolar Professor Tibúrcio de Freitas, o senhor Hercílio de Faveri, assumiu a direção aos 22 anos de idade, permanecendo na função de diretor da escola durante 9 anos. De acordo com a reportagem, para o jornal Panorama de Urussanga /SC, sua forma de administrar o grupo escolar era exemplar, pois era um homem enérgico, de pulso firme que não precisava falar, pois seu olhar transmitia ordem e respeito. (PANORAMA, 2011, p. 1)

Saberes Pedagógicos, Criciúma, v. 4, nº 1, janeiro/abril 2020.- Curso de Pedagogia- UNESC 


\section{SABERES PEDAGÓGICOS}

Revista do Curso de Graduaçāo de Pedagogia - Unesc

ISSN $2526-4559$

No Livro de Lançamento de Notas de Honra dos Alunos (23 de fevereiro de 1928 a 28 de março de 1941) consta que os primeiros alunos a receberem a homenagem no dia 5 de novembro de 1929 foram: Cesar Cechinel Junior ( $4^{\circ}$ ano) e Bruno Mariotti ( $3^{\circ}$ ano). O livro tem sua data inicial em 1928 como Grupo Escolar Professor Tibúrcio de Freitas, segue com esta denominação até 1940, sendo que desta data em diante segue até o ano de 1971, como Grupo Escolar Barão do Rio Branco. Neste período foram realizadas 1.108 homenagens a alunos e alunas do $1^{\circ}$ ao $4^{\circ}$ ano.

Figura 3 e 4: Páginas do Livro de Lançamento das Notas de Honra dos Alunos do Grupo Escolar Professor Tibúrcio de Freitas (23 de fevereiro de 1928 a 28 de março de 1941).
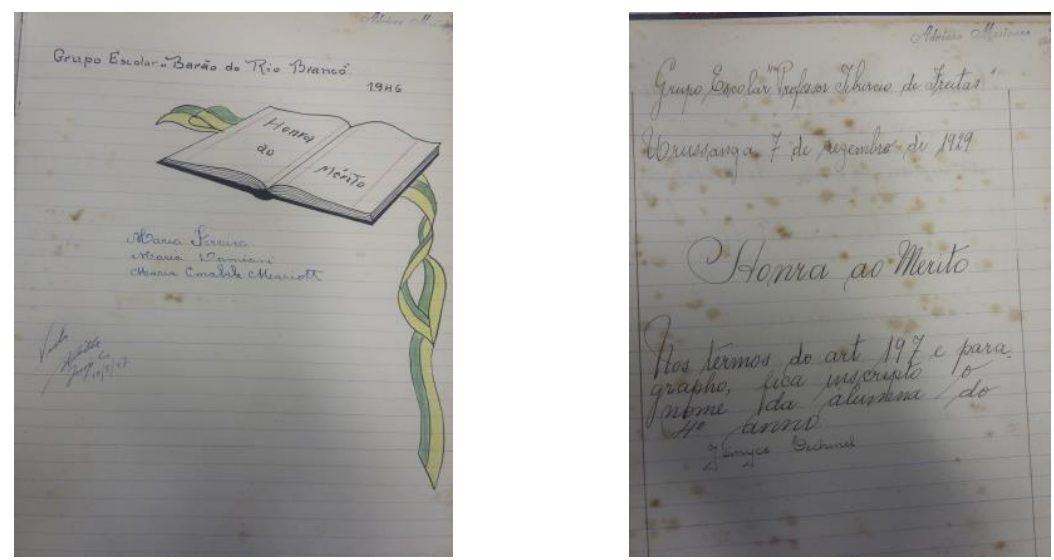

Fonte: Acervo da Escola Ensino Básico Barão do Rio Branco.

No Livro de Atas de Promoção de Exames dos Alunos da Escola Complementar de Urussanga (15 de fevereiro de 1934 a 27 de março de 1941), os livros contêm 50 folhas, mas descrições: nome do aluno, data nascimento, ano de conclusão e observações.

No Livro de Registro de Sabatinas dos Alunos da Escola Complementar de Urussanga (15 de fevereiro de 1934 a 24 de julho de 1941) encontramos nas primeiras páginas as notas dos alunos/as de $1^{\circ}$ ano, com a seguinte estrutura: número de matrícula, nome do aluno, bem como as disciplinas: Português, Francês, Aritmética, Geografia, Geometria, História, História do Brasil, Educação, Desenho, Trabalhos, Música e Ginástica, além da média geral ou de promoção e observações. A partir dos anos de 1935, a descrição passa a ser Escola Normal Primária de Urussanga seguindo esta designação até 1940. O diretor à época era o senhor Djalma Bento.

Saberes Pedagógicos, Criciúma, v. 4, nº 1, janeiro/abril 2020.- Curso de Pedagogia- UNESC 
Estas informações levam a inferir que dentro do Grupo Escolar Professor Tibúrcio de Freitas, funcionou a Escola Complementar de Urussanga e a Escola Normal Primária de Urussanga, além disso, a escola contou com distintos diretores/as e professores/as. No próximo item serão problematizadas as lembranças dos sujeitos desta pesquisa.

\section{LEMBRANÇAS SOBRE AS EXPERIÊNCIAS ESTUDANTIS DO GRUPO ESCOLAR PROFESSOR TIBÚRCIO DE FREITAS.}

Os relatos obtidos por meio de entrevistas nos direcionam para uma melhor compreensão do cotidiano do Grupo Escolar Professor Tibúrcio de Freitas, no contexto educacional de Urussanga (SC), entre 1928 a 1941. Estes relatos representam lembranças de um espaço de convívio e de experiências que marcou a vida de muitas pessoas, ou seja, o ambiente escolar. Conforme Nunes (2003, p. 15), as escolas são:

\footnotetext{
[...] "celeiros de memórias", espaço nos quais se tece parte da memória social. As reminiscências desse espaço são possíveis pela estrutura de suas rotinas e sua continuidade no tempo. A importância dessa instituição, mesmo quando apontamos sua crise na construção das subjetividades do mundo contemporâneo, reside no fato de representar, durante a infância e adolescência, para além de sua finalidade específica, um território de lenta aprendizagem do mundo exterior. Os códigos desse universo transparecem na definição de um espaço que lhe é próprio, no uso do tempo, nas regras disciplinares, nas vestimentas específicas e numa pluralidade de objetos.
}

Os três ex-alunos/as senhor Armando Ferdinando Bettiol, Inez Gema Dal Bó Daminani, Lúcio Olivier Guissi, que iniciaram seus estudos no Grupo Escolar Professor Tibúrcio de Freitas posteriormente migraram para o Grupo Escolar Barão do Rio Branco. O senhor Lúcio Olivier Guissi (93 anos) nascido em 09 de abril de 1925, veio de Azambuja (Tubarão /SC), onde fez o curso primário. Ingressou no Grupo Escolar Professor Tibúrcio de Freitas, aos 13 anos de idade, para fazer o Curso Complementar. No ano de 1941 foi orador oficial, representando os estudantes, no ato de inauguração do Grupo Escolar Barão do Rio Branco, fazendo as honras ao então governador senhor Nereu Ramos. Filho de Ignácio Guissi e Maria Olivier Guissi, em seu primeiro casamento senhor Lúcio teve 4 filhos. Logo após o falecimento de sua esposa, o senhor Lúcio casou-se novamente com a senhora Vera Cancelier

Saberes Pedagógicos, Criciúma, v. 4, nº 1, janeiro/abril 2020.- Curso de Pedagogia- UNESC 
em 1976, com quem teve mais um filho. Hoje tem cinco netos e dois bisnetos. Era comerciante na cidade de Urussanga, seu armazém tinha o segmento de gêneros alimentícios, após se aposentar fazia cálculo do Imposto de Renda, de amigos e pessoas que precisavam do serviço, para fins de aposentadoria.

Figura 5: Lúcio Olivier Guissi (16 de outubro de 2018)

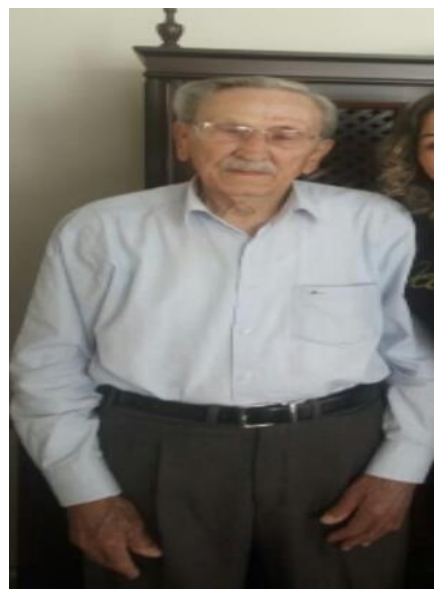

Fonte: Acervo pessoal da pesquisadora

O senhor Armando Ferdinando Bettiol (88anos) nascido em 20 de julho de 1930, iniciou seus estudos no Grupo Escolar Professor Tibúrcio de Freitas, em seguida foi para o Grupo Escolar Barão do Rio Branco, em 1941. Ele também participou do ato de inauguração do novo grupo escolar. O senhor Armando aparece nos registros escolares como melhor aluno do educandário, com classificação "forte", obtendo nota máxima em todos os quesitos. Casado com a sra. Ruth Mainatti, com quem teve três filhos/as, dois meninos e uma menina. Tem três netos/as. O senhor Armando recorda de muitos detalhes sobre a época escolar que estudou no Grupo Escolar Professor Tibúrcio de Freitas. O mesmo relata acontecimentos não só relacionados com o grupo escolar, mas também com o desenvolvimento social da cidade de Urussanga.

Quando terminou o Tibúcio lá em cima, por que aquilo lá era da igreja, foi para a Prefeitura. Depois, lá em cima foi Cadeia Pública uns três ou quatro anos. Lembrome quando eu completei 18 anos, em 1948, a grade do xadrez quem derrubou foi eu. Depois, então, voltou para Igreja e o Pe. Agenorfazia uns dois anos que estava aqui, 


\section{SABERES PEDAGÓGICOS}

Revista do Curso de Graduaçāo de Pedagogia - Unesc

ISSN 2526-4559

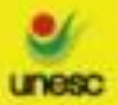

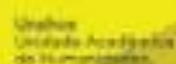

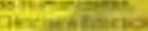

edunesc

então a primeira coisa que ele fez foi fundar o Jardim de Infância lás . (BETTIOL, 2017, p. 8).

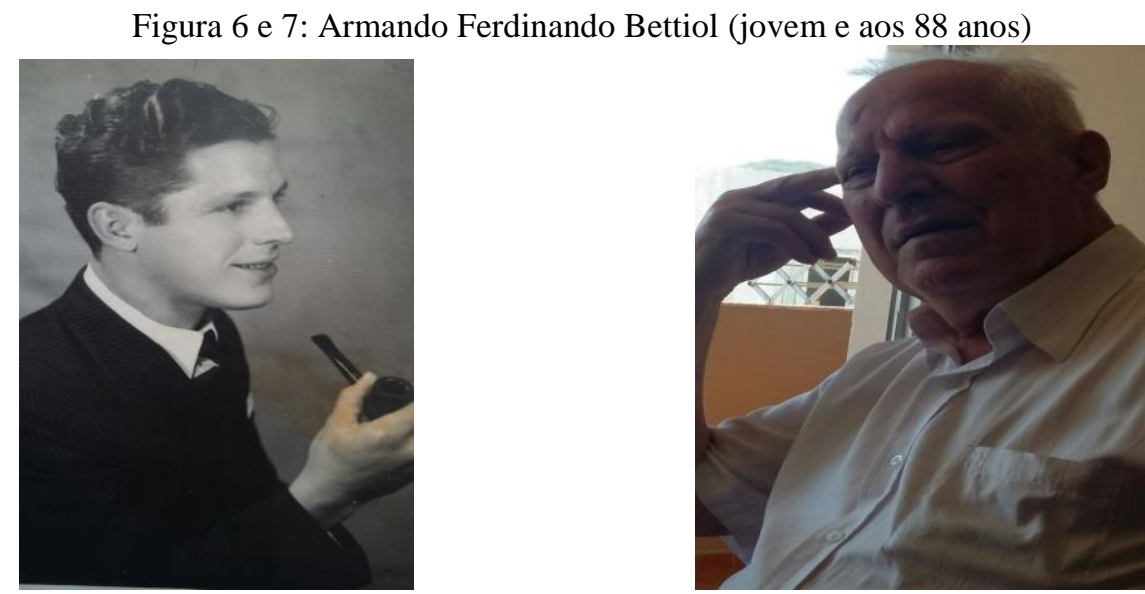

Fonte: Figura 6 - Arquivo pessoal do mesmo.

Figura 7 - Acervo pessoal da pesquisadora

A senhora Inez Gema Dal Bó Daminani (90 anos), nascida em 22 de maio de 1928, recorda que veio do Rio Caeté para se hospedar na casa do senhor Hercílio de Faveri professor do Grupo Escolar Professor Tibúrcio de Freitas, onde somente estudava, sendo que seu pai pagava pela sua estadia. Logo após fez parte do Grupo Escolar Barão do Rio Branco, onde era colega de classe do senhor Lúcio. Casada com o senhor Ladir Rosalino Damiani, teve somente uma filha.

O que mais nos chamou atenção nos depoimentos dos/as entrevistados/as foi o fascínio que os mesmos ainda têm por seus/as professores/as e seus aprendizados escolares. Os/as três lembram do professor e diretor, o senhor Hercílio de Faveri, homem enérgico e o respeito que tinham por ele. Lembram também da professora Orcy Silva Bez Batti, que lecionava Língua Portuguesa e que para eles/as era uma excelente professora. O senhor Armando Ferdinando Bettiol, lembra detalhadamente de seus professores:

A primeira professora foi Janice Cechinel, a segunda Odeth Birc Costa, que vem a ser a sogra da Márcia Costa. A outra foi Orcy Silva Bez Batti, casada com Mamon Bez Batti, tem um filho que mora em Criciúma e é casado com uma moça do Fontana, parece. Tinha o Hercílio de Faveri, que era o diretor aqui e lá em cima era

\footnotetext{
${ }^{5}$ Este edifício, mais tarde passou a ser conhecido como Casa Lar Paraíso da Criança. Nele, o Pe Agenor Neves Marques recebia crianças de famílias pobres da região. Esta foi uma das obras assistencias mais importantes da região.
}

Saberes Pedagógicos, Criciúma, v. 4, nº1, janeiro/abril 2020.- Curso de Pedagogia- UNESC 
o Djalma Bento, senhor de Araranguá, primeiro diretor do Tibúrcio (BETTIOL, 2017, p. 2).

No Grupo Escolar haviam vários/as professores/as, as disciplinas eram: Português, Francês, Aritmética, Geografia, Geometria, História, História do Brasil, Educação, Desenho, Trabalhos, Música e Ginástica. O gosto por aprender se destacava entre os/as entrevistados/as, como já foi mencionado. Eles recordam da escola com brilho nos olhos. Relatam que as dificuldades, como distância entre a escola e a casa e os afazeres domésticos eram facilmente superados diante do fascínio pelo aprender.

Em suas lembranças, os uniformes deveriam ser limpos, as unhas cortadas, a higiene era também um item a ser avaliados nos/as alunos/as. Não bastava ser bom/boa aluno/a, teria que estar de acordo com as exigências do então grupo escolar. No Ao Grupo Escolar Professor Tibúrcio de Freitas não havia uniforme, o uso do mesmo passou a ser realidade a partir de 1941, quando há a transferência de local e de denominação, ou seja, quando eles/as ingressam no Grupo Escolar Barão do Rio Branco. Lá o uniforme era camisa branca, short azul marinho para os meninos e para as meninas saia da mesma cor. Este detalhe é reforçado pelas memórias do senhor Armando e da senhora Gema, respectivamente: "No Tibúcio não tinha uniforme, passou a ter aqui calça azul curta, até a 4 série e camisa branca de manga curta” (BETTIOL, 2017, p.2). “Aqui [Grupo Escolar Barão do Rio Branco] era era saia azul marinho, pregueada, suspensório, uma golinha com duas tirinhas e uma blusa branca" (DAMIANI, 2018, p.4).

O castigo escolar era um recurso pedagógico utilizado para conter os/as alunos/as indisciplinados/as. O castigo dado ao aluno Zeca Escaravaco, tido à época como um dos mais desobedientes, foi lembrado pelo senhor Armando. O temido castigo era como marca registrada, quem o recebia ficava "marcado" entre os colegas de classe e a comunidade. Os castigos eram reconhecidos e legitimados como uma forma de tentar garantir as normas escolares, a fim de obter um comportamento disciplinado por parte de alunos e alunas.

O senhor Armando conta que foi castigado pelo professor Hercílio de Faveri, mas que sua punição foi mais branda, pois quando inquirido pelo professor sobre uma ocorrência escolar, acabou falando a verdade. Não deixou de cumprir com sua sentença, mas acredita, que foi uma forma de reeducá-lo para que ele não voltasse a cometer este erro novamente. $\mathrm{Na}$

Saberes Pedagógicos, Criciúma, v. 4, nº 1, janeiro/abril 2020.- Curso de Pedagogia- UNESC 
sua avaliação, o castigo era uma forma de garantir o aprendizado e, ao mesmo tempo, uma maneira de fazer com que os/as alunos/as não repetissem mais os erros cometidos. Sobre os tipos de castigos ele relata:

Existiam castigos como apanhar de régua, eu nunca apanhei, mas a maioria que estudava comigo, e moça também. Era palma na mão e reguada, tinha aquela varinha de vime também. De joelho, tinha o quadro, então de costas para o quadro de joelho, olhando para os colegas e eles olhando pra ti fazendo careta, gozando e tu tinha que ficar quieto, quanto mais você se mexia ou falava mais tempo ficava ali. (BETTIOL, 2107, p.4).

Feito da forma que os/as alunos/as ficassem expostos/as, era um jeito de demonstrar para os/as demais que a punição poderia ser aplicada a qualquer um e a qualquer momento. Ou seja, o/as aluno/as que sofria algum tipo de castigo servia de exemplo para os/as outros/as que ousassem infringir as regras ou não tivessem um bom desempenho escolar. Esta prática escolar remonta aos anos oitocentistas no Brasil conforme afirmam Aragão e Freitas (2012, p. 18):

\begin{abstract}
Nos anos de 1800, os castigos físicos tinham dois fins: punir o mau comportamento e a dificuldade de aprendizagem. Férulas, chicotes e palmatórias faziam parte dos objetos utilizados pelo professor para educar os alunos, mantendo a ordem e a disciplina. Todavia, tais práticas acabaram por denunciar uma sociedade impregnada de práticas violentas, sendo comuns não apenas no universo escola, mas em todo o processo que envolvia relações humanas.
\end{abstract}

O ensino, na avaliação do senhor Armando Ferdinando Bettiol, tinha traços tradicionais, no sentido de que a memorização era essencial para tornar o/as aluno/as nota dez. A este respeito ele relata:

Por exemplo: passava a lição no quadro, você fazia ou levava para o professor olhar, tá certo tá, não tá faz de novo, depois apagava, você tinha que ter uma memória muito boa. Não tinha caderno, lápis e nada, só tinha essa lousa, no $4^{\circ}$ ano é que passou a ter história, geografia, daí passou a ter caderno. A pessoa tinha que estudar, prestar a atenção para aprender, tinha que memorizar, entendeu? (BETTIOL, 2017, p.9).

Estas lembranças do senhor Bettiol faz pensar sobre o método de ensino que marcou não só esta geração, mas deixou marcas nas gerações seguintes, chegando até a contemporaneidade. A escola tradicional subsistiu, mesmo no contexto de inovação educacional demarcado pela introdução do Grupo Escolar. Há indícios, a partir destas lembranças que o castigo e a memorização foram bastante utilizados enquanto recurso

Saberes Pedagógicos, Criciúma, v. 4, nº1, janeiro/abril 2020.- Curso de Pedagogia- UNESC 
pedagógico. O processo de passagem de uma pedagogia tradicional para uma pedagogia moderna, parece não se tratar de um processo linear, há avanços e retrocessos, permanências e descontinuidades.

Para compreendermos os processos de mudança, precisamos compreender qual o modelo educacional que é reconhecido em cada período pela sociedade como sendo o correto, o mais eficaz, caso contrário cairemos na armadilha dos julgamentos. Portanto, é preciso compreender o que se espera da escola e do professor, contextualizando temporal e espacialmente. Ser professor de um grupo escolar no interior de Santa Catarina, não era a mesma coisa que atuar em um Grupo Escolar situado na capital do Estado. Mas, isso não nos impede de pressupor que o respeito ao professor, tão propalado naquela época, fosse alcançado muito mais pelo medo do que propriamente pelo respeito em si e o recurso, neste caso, só poderia ser o castigo escolar, que traz consigo a naturalização do emprego da violência e do autoritarismo.

\section{CONCLUSÃO}

A criação do Grupo Escolar Professor Tibúrcio de Freitas não foi algo dissociado de um movimento maior, nacional e internacionalmente, que buscava concretizar nas capitais e nas cidades periféricas, um novo modelo educacional que deveria se contrapor à educação tradicional, ainda muito presente no início do século XX, no Brasil.

No cenário urussanguense esta escola oportunizou que várias crianças, independente do gênero se alfabetizassem e cursassem os quatro anos da escola primária, algo obrigatório por lei neste período.

A preservação de alguns documentos do Grupo Escolar Professor Tibúrcio de Freitas no acervo documental da EEB Barão do Rio Branco foi fundamental para a realização deste trabalho, o que reafirma a ideia de que os arquivos e os seus documentos vem adquirindo importância crescente para os pesquidadores e pesquisadoras do campo da história da educação. Ele traz informações sobre o cotidiano das práticas escolares e a partir de seus documentos é possível reconstruir a trajetória das instituições escolares. O fato da EEB Barão do Rio Branco estar entre as escolasa abarcadas pelo Centro de Memória da Educação do Sul

Saberes Pedagógicos, Criciúma, v. 4, nº 1, janeiro/abril 2020.- Curso de Pedagogia- UNESC 
de Santa Catarina contribui para uma cultura de preservação deste patrimônio escolar, na contramão de uma lógica sustentada pela forte cultura do descarte sem critérios vivenciada por boa parte das instituições.

Os testemunhos orais, assim como os documentos, compoem um conjunto importante de fontes imprescindíveis para compreendermos os vários movimentos pedagógicos que historicamente atravessaram a instituição escolar. No caso deste estabelecimento, é possível afirmar, que a escola tradicional subsistiu, mesmo no contexto de inovação educacional demarcado pela introdução do Grupo Escolar. Há indícios, a partir das lembranças dos/as ex-alunos/as que o castigo e a memorização foram bastante utilizados enquanto recursos pedagógicos. O processo de passagem de uma pedagogia tradicional para uma pedagogia moderna parece não se tratar de um processo linear, há avanços e retrocessos, permanências e descontinuidades.

\section{REFERÊNCIAS:}

ARAGÃO, Milena; FREITAS, Gonçalves Anamaria. Práticas de castigos escolares: enlaces históricos entre normas e cotidiano. Caxias do Sul/SC, 2012.

BALDIN, Nelma. Tão fortes quanto a vontade, história da imigração italiana no Brasil: os vênetos em Santa Catarina. Florianópolis: Insular; Editora da UFSC, 1999.

BETTIOL. Armando Ferdinando. Entrevista concedida a Shirlei Serafim de Oliveira, realizada na cidade de Urussanga- SC, no dia 14 de nov. de 2017.

CARDOSO, Maria Angélica; Hoff, Santino; Mafra, Antônio, Dias. A educação escolar de Santa Catarina no período do ciclo da erva-mate. Joaçaba/SC, 2007.

COSTA, Márcia Marques. Do Tibúrcio ao Barão. Panorama SC: Costa Editora e Gráfica, Urussanga/SC, 2011.

COSTA, David Antônio da. A Escola Ativa nos Grupos Escolares Catarinenses: o programa de Aritmética de 1946. Programa de Pós-Graduação em Educação Científica e Tecnológica da Universidade Federal de Santa Catarina - UFSC, 2016.

DAMIANI, Inez Gema Dal Bó. Entrevista concedida a Shirlei Serafim de Oliveira, realizada na cidade de Urussanga- SC, no dia 10 set. de 2018.

Saberes Pedagógicos, Criciúma, v. 4, nº 1, janeiro/abril 2020.- Curso de Pedagogia- UNESC 


\section{SABERES PEDAGÓGICOS}

Revista do Curso de Graduaçāo de Pedagogia - Unesc

ISSN 2526-4559

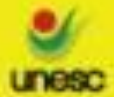

GUISSI, Lúcio Olivier. Entrevista concedida a Shirlei Serafim de Oliveira, realizada na cidade de Urussanga- SC, no dia $1^{\circ}$ de agost. de 2017.

LUDKE, Menga; ANDRÉ, Marli E.D.A. Pesquisa em educação: abordagens qualitativas. São Paulo, Editora Pedagógica e Universitária, 1986. 99p.

MARZANO, Luigi. Colonos e Missionários Italianos na Floresta do Brasil. Florianópolis: Ed. UFSC, 1985.

OLIVEIRA, Cristiano Lessa de. Um Apanhado Teórico- Conceitual sobre a Pesquisa Qualitativa: Tipos, Técnicas e características. Doutorando pertencente ao Programa de PósGraduação em Letras e Linguística da Universidade Federal de Alagoas. Disponível em: file:///C:/Users/shirlei/Desktop/UM\%20APANHADO\%20TE\%C3\%93RICO-

CONCEITUAL\%20SOBRE\%20A\%20PESQUISA.pdf. Acesso em: 31 de outubro de 2018.

O Acervo Digital do Centro de Memória da Educação do Sul de Santa Catarina (CEMESSC), coordenado pelo Grupo de História e Memória da Educação (GRUPEHME), Disponível em: http://www.bib.unesc.net/muesc/muni_07.php. Acesso em: 23 de agosto de 2018.

MAGALHÃES, Justino. Um apontamento metodológico sobre a história das instituições educativas. In: SOUSA, Cynthia Pereira de e CATANI, Denice Bárbara (orgs.) Práticas Educativas, Culturas Escolares, Profissão Docente. São Paulo: Escrituras Editora. p. 51-68, 1988.

MOGARRO, Maria João. Arquivos e educação: a construção da memória educativa. Revista brasileira de história da educação n 10 jul./dez. 2005 p.p. 75-99.

NORA, Pierre. Entre memória e história. A problemática dos lugares. Prog. História, São Paulo, PUC-SP, (10): 7-29, 1993.

NUNES, Clarice. Memória e história da educação: entre práticas e representações. In: LEAL, Maria Cristina e PIMENTEL, Marília Araújo Lima. História e memória da escola nova. São Paulo: Loylola, 2003.

ROSSI, Edneia Regina. Escolas reunidas e grupos escolares: traços da modernidade técnico-científica no ensino elementar (1889-1929). Programa de Pós-graduação em Educação, Universidade Estadual de Maringá. Paraná, 2017.

SANTANA, Dorival Aparecido de. A Escola como Lugar de Memórias e de Identidades: um estudo a partir de escritos de alunos do ensino médio do Colégio E.N.S de Lourdes. Londrina /PR, 2013-2014. 
SANTOS, Alessandra de Souza; JACOMELLI, Mara Regina Martins. A Arquitetura dos

Grupos Escolares Paulistas: O Grupo Escolar Coronel Flamínio Ferreira de Camargo/ Limeira? SP. In: VIII Jornada do HISTEDBR, 2008, São Carlos. Anais VIII Jornada do HISTEDBR. Campinas: HISTEDBR, 2008. p. 1-12.

SELAU, Maurício da Silva. A ocupação do território Xokleng pelos imigrantes italianos no sul catarinense (1875-1925): resistência e extermínio. Dissertação (Mestrado) Universidade Federal de Santa Catarina. Programa de Pós-graduação em História. Florianópolis, 2006.

SILVA, Vera Lucia Gaspar. Vitrines da República: Os Grupos Escolares em Santa Catarina (1889 -1930). Uberlândia: VI Congresso Luso- Brasileiro de História da Educação, 2006.

SOUZA, Thuysa Schlichting de. Ensino de Aritmética no Livro Didático da Escola Nova de Miguel Aguayo: reverberações do escolanovismo em Santa Catarina, 2016.

TIBÚRCIO, Grupo Escolar Professor. Grupo de Pesquisa História e Memória da Educação. RABELO, Giani; COSTA, Marli de Oliveira (Coord) Centro de Memória da Educação do Sul de Santa Catarina. Escola de Educação Básica Barão do Rio Branco: Documentos disponibilizados - v.1. Criciúma, SC: GRUPEHME, 2010. 1 DVD Disponível em: http://www.bib.unesc.net/pergamum/biblioteca/index.php. Acesso em: 05 de nov. de 2018.

TRENTO, Ângelo. Do outro lado do Atlântico: um século de imigração no Brasil. São Paulo: Nobel, 1989.

VENDRAMINI, Lucimary. Urussanga: Da escola italiana à escola pública. Santa Catarina, 2003. 74f. Dissertação (Mestrado em Engenharia de Produção) - Programa de Pós Graduação em Engenharia de Produção, Universidade Federal de Santa Catarina, Florianópolis. Disponível em: https://core.ac.uk/download/pdf/30366105.pdf Acesso em: 15 set. de 2018. 